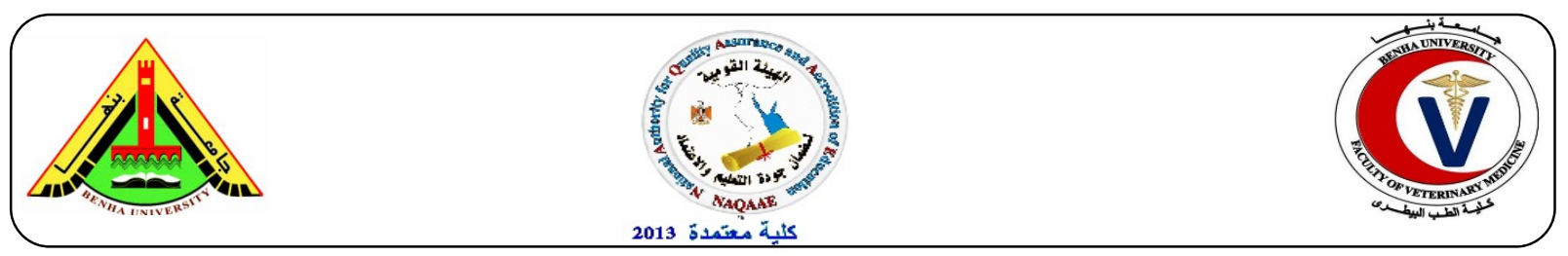

\title{
Utility of laboratory animals for relative potency evaluation of bovine respiratory viral vaccine
}

\author{
Effat L. El Sayed ${ }^{1}$; Hanaa A. Mostafa ${ }^{2}$ and Nermeen G. Shafik ${ }^{2}$ \\ *Veterinary Serum and Vaccine Research Institute, Abbasia, Cairo, Egypt \\ **Central Laboratory for Evaluation of Veterinary Biologics, Abbasia, Cairo, Egypt.
}

\section{A B S T R A C T}

Current potency assay of bovine respiratory viral vaccines is routinely focused on vaccination antibody assay model in susceptiblecattle. Based on the published data among validity of rabbits as a laboratory animals that could be used to evaluate potency of many veterinary vaccines and difficulty in finding seronegative cattle to be used in potency assay of bovine respiratory viral vaccines plus the need to carry batch to batch release potency test in less expensive way, The present study was undertaken to address utility of rabbits for relative potency assay of a combined inactivated vaccine of IBR, BVD,PI3 and BRS viruses in comparison with susceptible calves.Each of two batches of the local vaccine and one imported vaccine was inoculated intramuscularly twice 14 days apart into one group of three seronegative cattle calves using its recommended dose, and one group of five adult bosket rabbits using $2 / 5$ cattle dose of each vaccine. The test vaccine dose dependent immune response assays in calves and rabbits were conducted by inoculation of each of $1 / 2,1 / 4$ and $1 / 8$ the full dose of the tested vaccine in one group of each calves and rabbits. Serum samples were collected and measured by serum neutralization test. The tested vaccines were induced mean neutralizing antibody titer averages of (1.05 - 1.5), (1.5 - 1.56), (1.05 - 1.64) and (1.42 - 1.52) $\log _{10}$ in sera of immunized rabbits for BVD, IBR, PI-3 and BRS viruses respectively,and $\left(1.65\right.$ - 1.75),(1.5 - 1.8), (1.44 - 1.9) and (1.6 - 1.65) $\log _{10}$ in sera of vaccinated calves for the same viruses respectively by the $3^{\text {th }}$ weekafter boostering; test vaccines seem to be potent in calves and immunogenic in rabbits.Averages of the Relative Potency ( RP ) that determined by dividing each mean virus neutralization antibody titer of $\log _{10}$ in sera of the immunized rabbits by that of the vaccinated calves were $(0.6-0.8),(0.8-1.0),(0.5-0.8)$ and $(0.8-$ $0.9)$ for each of BVD, IBR, PI3 and BRS viruses respectively by the $3^{\text {th }}$ weekafter boostering. However, the results of the vaccine dose dependent-immune response in both of immunized rabbits and vaccinated calves are proved the sensitivity of rabbits in parallel with calves to the reduced doses of one of the tested vaccines; the reduced doses of the vaccine were induced a considerable regressed antibody titers in serum of immunized rabbits as in vaccinated calves. In conclusion, the present data indicate that the rabbits constitute as useful suggestive laboratory animals for potency evaluation of the bovine combined respiratory inactivated viral vaccines instead of cattle calves.

KEY WORDS: rabbits, potency evaluation, viral vaccines.

(http://www.bvmj.bu.edu.eg)

(BVMJ-32(1): $41-44,2017)$

\section{INTRODUCTION}

The effective prophylactic vaccination was one of the control and preventive measures against bovine respiratory disease complex (BRDC) (Durham and Hassard, 1990) which is the most prevalent and costly disease affecting the cattle industry (Callan and Garry, 2002). Bovine Viral Diarrhea virus (BVD), Infectious Bovine Rhinotracheties (IBR) virus Para-Influenza-3 (PI-3) virus and Bovine Respiratory Syncytial (BRS)virus represent the most important pathogens associated with Bovine respiratory disease complex leading to drastic upset among calves (Juarez - Burraceet al., 2003). Rabbits have been used in laboratory work, in research and vaccine testing; it proposed to be used in immunogenicity evaluation of inactivated equine herpes virus vaccine (British Pharmacopoeia Veterinary, 2005). Also, many authors succeeded to use the rabbits for evaluation of different types of veterinary and human vaccines (Lupton and Reed, 1980, Tsenova et al., 2006 and Ahmad et al., 2012). The specific antibody response to vaccination with inactivated viral vaccine has been considered a major indicator of such vaccine potency (Fulton et al., 1995 and Kerkhofs et al., 2004).

The current study aimed to assess utilityofthe rabbits as a laboratory animal and alternative cheap and easy model to test the immunogenicity of the 
combined inactivated vaccine against BVD, IBR, PI-3 and BRS viruses instead of susceptible calves.

\section{MATERIAL AND METHODs}

\subsection{Animals:}

\subsubsection{Calves:}

Twenty-one calves of approximately six months old and proved seronegative against BVD, IBR, PI-3 and BRS as screened by SNT were used to evaluate the potency and dose response of the vaccines under testing (three calves/group).

\subsubsection{Rabbits:}

Thirty-five adult Boskat rabbits of about $2.5 \mathrm{~kg}$ body weight each were used to evaluate the potency and dose response of the vaccines under testing (five rabbits/group).

All animals were kept under hygienic conditions receiving balanced ration and adequate water before and after vaccination.

\subsection{Cell culture:}

Monolayer cell cultures of Madine Darby Bovine Kidney (MDBK) cell line proved to be free from non-cytopathic BVDV strain were grown, maintained and used to conduct serum neutralization test. The cell line obtained from Rinder pest like disease department, Veterinary serum and vaccine research institute, Abbasia, Cairo, Egypt.

\subsection{Viral strains:}

Bovine Viral Diarrhea(BVD) virus; Iman strain, Infectious Bovine Rhino-tracheitis (IBR) virus; Abou-Hammad Strain, Para Influenza-3virus; strain 45and Bovine Respiratory Syncytial (BRS) virus; 375Lstrainwere used to carry out serum neutralization test.

\subsection{Vaccines:}

Two different batches of the localcombined inactivated (Pneumo-4) and one batch of an imported vaccine against BVD, IBR, PI-3 and BRS were tested for potency and dose response assay in calves and rabbits.

\subsection{Serum Neutralization Test (SNT):}

It was performed on MDBK cell line monolayer cultures tissue culture microtiter plates using 100 $\mathrm{TCID}_{50}$ of each virus against a serial two-fold dilutions of serum samples (Rossi and Kiessel, $1971)$ and the antibody titer was expressed as $\log _{10}$.

\subsection{Experimental design:}

Each of the tested vaccines was inoculated intramuscularly in three calves using its recommended dose and in five rabbits using its $2 / 5$ cattle dose, and 14 days later with the same dose and rout of inoculation as a booster dose. Groups of three calves and five rabbits were kept as negative controls.

Two and three weeks after second inoculation, individual serum samples were collectedfrom the inoculated and negative control animals. Each of $1 / 2,1 / 4$ and $1 / 8$ the cattle dose of one batch of the tested vaccines was inoculated in group of three calves, and each $1 / 2,1 / 4$ and $1 / 8$ the rabbit dose of the tested vaccine group of five rabbits, and 14 days later with the same dose and rout of inoculation as a booster dose. Two and three weeks after the booster dose inoculation, individual serum samples were collected from the inoculated animals.

The collected serum samples were inactivated by heating in water bath at $56^{\circ} \mathrm{C}$ for 30 minutes then stored at $-20^{\circ} \mathrm{C}$ till examined for the vaccine viruses neutralizing antibodies.

\section{RESULTS}

The achieved results in this study declared the immune response against each viral component of the tested vaccines in inoculated calves and rabbits (Table 1). Table (2) showed that the reduced doses of the vaccine were induced a considerable regressed antibody titers in serum of immunized rabbits as in vaccinated calves. The half cattle dose was capable to induce a relative protective antibody titer for each viral component by the third week after boostering.

\section{DISCUSSION}

This study aimed to assess the possibility to use rabbits as laboratory animal model in potency evaluation of inactivated respiratory vaccines in replacement of the original host (calves).

Table (1) summarizes the immune response against each viral component of the tested vaccines in inoculated calves and rabbits, it was found that the batches induced mean neutralizing antibody titer averages of (1.5 - 1.65), (1.2 - 1.5), (1.3 -1.8) and $(1.3-1.5) \log _{10}$ in sera of vaccinated calves, and (1.35 - 1.59), (1.2 - 1.4), (1.05) and (1.05 - 1.5) $\log _{10}$ in sera of immunized rabbits for BVD, IBR, PI-3 and BRS viruses respectively by the $2^{\text {nd }}$ week after second vaccination, and (1.65 - 1.75), (1.5 $1.8),(1.44-1.9)$ and $(1.6-1.65) \log _{10}$ in vaccinated calves, and (1.05 - 1.5), (1.5 - 1.56), (1.05 - 1.64) and $(1.42-1.52) \log _{10}$ in immunized rabbits for 
Table (1): BVD, IBR, PI-3 and BRS viruses - mean neutralizing antibodies in the sera of animals vaccinated with combined inactivated vaccines.

Mean serum neutralizing antibody titer $\left(\log _{10}\right)$

\begin{tabular}{|c|c|c|c|c|c|c|c|c|c|c|c|c|c|}
\hline \multirow{3}{*}{\multicolumn{2}{|c|}{ Time of Sampling }} & \multicolumn{12}{|c|}{ Mean serum neutralizing antibody titer $\left(\log _{10}\right)$} \\
\hline & & \multicolumn{4}{|c|}{$\begin{array}{c}\text { Batch } 1 \\
\text { (local vaccine) }\end{array}$} & \multicolumn{4}{|c|}{$\begin{array}{c}\text { Batch } 2 \\
\text { (local vaccine) }\end{array}$} & \multicolumn{4}{|c|}{$\begin{array}{c}\text { Batch } 3 \\
\text { (imported vaccine) }\end{array}$} \\
\hline & & BVD & IBR & PI-3 & BRS & BVD & IBR & PI-3 & BRS & BVD & IBR & PI-3 & BRS \\
\hline \multirow{2}{*}{ Zero day } & $\mathrm{R}$ & - & - & - & - & - & - & - & - & - & - & - & - \\
\hline & $\mathrm{C}$ & 0.22 & 0.35 & 0.35 & 0.3 & 0.37 & 0.3 & 0.15 & 0.35 & 0.40 & 0.25 & 0.3 & 0.30 \\
\hline \multirow{3}{*}{$2 \mathrm{WPB}$} & $\mathrm{R}$ & 1.59 & 1.2 & 1.05 & 1.35 & 1.35 & 1.38 & 1.05 & 1.5 & 1.35 & 1.4 & 1.05 & 1.2 \\
\hline & $\mathrm{C}$ & $1.5^{*}$ & 1.2 & 1.3 & 1.35 & 1.5 & 1.5 & 1.8 & 1.30 & 1.65 & 1.5 & 1.7 & 1.5 \\
\hline & $\mathrm{RP}$ & 1.06 & 1 & 0.8 & 1 & 0.9 & 0.9 & 0.5 & 1.1 & 0.8 & 0.9 & 0.8 & 0.8 \\
\hline \multirow{3}{*}{$3 \mathrm{WPB}$} & $\mathrm{R}$ & 1.05 & 1.5 & 1.2 & 1.5 & 1.5 & 1.52 & 1.64 & 1.52 & 1.35 & 1.56 & 1.05 & 1.42 \\
\hline & $\mathrm{C}$ & 1.65 & 1.5 & 1.44 & 1.6 & 1.75 & 1.65 & 1.9 & 1.63 & 1.70 & 1.80 & 1.9 & 1.65 \\
\hline & $\mathrm{RP}$ & 0.6 & 1 & 0.8 & 0.9 & 0.8 & 0.9 & 0.8 & 0.9 & 0.79 & 0.8 & 0.5 & 0.8 \\
\hline
\end{tabular}

Zero day $=$ test before vaccination. * Arithmetic mean neutralizing titer expressed as $\log 10 .-=$ Negative. $\mathrm{R}=\mathrm{Rabbits} . \mathrm{C}=$ Calves. WPB = weeks post booster dose. N.B: Negative control calves and rabbits give negative results by the end of the test. $\mathrm{RP}=$ Relative potency.

Table (2): BVD, IBR, PI-3 and BRS viruses - mean neutralizing antibodies in the sera of animals vaccinated or immunized with reduced dose of the tested vaccine.

\begin{tabular}{|c|c|c|c|c|c|c|c|c|c|c|c|c|c|}
\hline \multirow{3}{*}{\multicolumn{2}{|c|}{ Time of Sampling }} & \multicolumn{12}{|c|}{ Mean serum neutralizing antibody titer $\left(\log _{10}\right)$} \\
\hline & & \multicolumn{4}{|c|}{$1 / 2$ Dose } & \multicolumn{4}{|c|}{$1 / 4$ Dose } & \multicolumn{4}{|c|}{ 1/8 Dose } \\
\hline & & BVD & IBR & PI-3 & BRS & BVD & IBR & PI-3 & BRS & BVD & IBR & PI-3 & BRS \\
\hline \multirow{3}{*}{ Zero day } & $\mathrm{R}$ & - & - & - & - & - & - & - & - & - & - & - & - \\
\hline & & & & & & & & & & & & & \\
\hline & $\mathrm{C}$ & 0.22 & 0.35 & 0.3 & 0.15 & 0.3 & 0.15 & 0.4 & 0.25 & 0.3 & 0.3 & 0.4 & 0.15 \\
\hline \multirow{2}{*}{$2 \mathrm{WPB}$} & $\mathrm{R}$ & 0.82 & 1.05 & 0.6 & 0.9 & 0.6 & 0.45 & 0.3 & 0.3 & - & - & - & - \\
\hline & $\mathrm{C}$ & 0.45 & 0.75 & 0.75 & 0.9 & 0.4 & 0.45 & 0.6 & 0.4 & - & - & - & - \\
\hline \multirow{2}{*}{$3 \mathrm{WPB}$} & $\mathrm{R}$ & 0.9 & 1.05 & 0.97 & 0.9 & 0.75 & 0.75 & 0.3 & 0.3 & - & - & - & - \\
\hline & $\mathrm{C}$ & 0.75 & 1.5 & 1.05 & 0.9 & 0.6 & 1.2 & 0.9 & 0.45 & - & - & - & - \\
\hline
\end{tabular}

Zero day $=$ Test before vaccination. $-=$ Negative. $\mathrm{C}=$ Calves. $\mathrm{R}=$ Rabbits. $\mathrm{WPB}=$ weeks post booster dose. 
BVD; IBR; PI-3 and BRS respectively, by the $3^{\text {th }}$ week after boostering. These titers are considered relatively adequate to protect the susceptible calves from such viral infections; the minimum acceptable serum neutralizing antibody titers were $0.9 \log _{10}$ for BVDV and $0.6 \log _{10}$ for IBRV, PI-3V and BRSV in cattle vaccinated with the live attenuated vaccines, (Zuffa and Feketeova, 1980 and Fulton et al., 1995).

Relative potencies (RPs) were determined by dividing the mean end titer of each virus neutralizing antibodies in sera of immunized rabbits by that of vaccinated calves for each of the tested vaccines. The average values of RP were $(0.8-1.0),(0.9-1.0),(0.5-0.8)$ and $(0.8-1.1)$ by the $2^{\text {nd }}$ week after second vaccination, and $(0.6$ $0.8),(0.8-1.0),(0.5-0.8)$ and $(0.8-0.9)$ by the $3^{\text {th }}$ week after boostering for each of BVD, IBR, PI.3 and BRS viruses respectively as shown in Table (1). Also, these results reveal that rabbits exhibited a distinct immune response resembling that developed by calves, and agree with that of (Ahmad et al., 2012) who reported that rabbits can be used as a compatible laboratory model for evaluation of inactivated respiratory viral vaccines.

However, the vaccine dose dependent immune response in immunized rabbits and vaccinated calves was studied by inoculation of serial reduced doses of one batch of the tested vaccines in order to declare specificity of the previously mentioned results. The reduced doses of the vaccine were induced a considerable regressed antibody titers in serum of immunized rabbits as in vaccinated calves; only the half cattle dose was capable to induce a relative protective antibody titer for each viral component by the $3^{\text {th }}$ week after boostering as shown in Table (2).

In conclusion, the present results reveal that rabbits' immune response against different viral components of the tested vaccines was relatively equal with that in vaccinated calves, and it could be used successfully for potency evaluation of the inactivated bovine respiratory virus vaccines saving cost and efforts.

\section{REFERENCES}

Ahmad M. Allam, Mohammad Karam ElBayoumy, Samira Said Taha and Magdy Mohammad Elsabbag 2012. Use of Rabbits as a Laboratory Model for Evaluation of the Combined Inactivated Respiratory Virus Vaccine (Pneumo-3) Adjuvanted by Montanide Oil (ISA 206). Global Veterinaria, 8(3), 254-258.

British Pharmacopoeia Veterinary 2005. Immunological Products, pp. 180-183.

Callan, R. J. and F. B. Garry 2002. Biosecurity and bovine respiratory disease. Vet. Clin. North Am. Food Anim. Pract., 18, 57-77.

Durham, P.J.K. and Hassard, L.E. 1990. Prevalence of antibodies to IBR, PI-3, BRSV and BVD in cattle in Saskatchewan and Alberta. Canadian Veterinary J., 31, 815-820.

Fulton, R.W., Confer, A.W., Burge, L.J., Perino, L.J., D'Offay, J.M., Paytom, M.E. and Mock, R.E. (1995): Antibody viral vaccines containing BHV, BVD, PI-3, BRSV immunogens and subsequent re-vaccination at day 140. Vaccine, 13, 725-733.

Juarez-Burrance, F.J., Chavezgris, G., and Garcia, R.E. 2003. Viral participation in respiratory disease in feedlot cattle, as identified by immune-histochemistry. Veterinaria Mexico 34, 1-12.

Kerkhofs, P., Tignon, M., Petry, H., Mawhinery, I., and Sustronck, B. 2004. Immune responses to bovine respiratory syncytial virus (BRSV) following use of an inactivated BRSV-PI3Mannheimia haemolytica vaccine and a modified live BRSV-BVDV vaccine. Vet. J., 167, 208-210.

Lupton, H.W. and Reed D.E. 1980. Evaluation of experimental subunit vaccines for infectious bovine rhinotracheitis. Am. J. Vet. Res., 41(3), 383-90.

Rossi, C. R. and Kiessel, G.K. 1971. Microtitre tests for detecting antibody in bovine serum to PI-3, IBRV and BVDV. Microbiol., 22, 32-3.

Tsenova, L., Harbacheuski, R., Moreira, A.L., Ellison, E., Dalemans, W., Alderson, M.R. Mathema, B. Reed, S.G., Skeiky, Y.A. and Kaplan, G. 2006. Evaluation of the Mtb72F polyprotein vaccine in a rabbit model of tuberculous meningitis. Infec. Imm., 74(4), 2392-2401.

Zuffa, A. and Feketeova, N. (980. Protective action of inactivated adjuvanted IBR virus vaccine against experimental infection. Veterinaria. Med., 25(21), 51-61. 